\title{
Remote ischaemic conditioning and remodelling following myocardial infarction: current evidence and future perspectives
}

\author{
A. P. Vanezis $^{1}$ - G. C. Rodrigo ${ }^{1}$ - I. B. Squire ${ }^{1}$ N. J. Samani ${ }^{1}$
}

Published online: 13 May 2016

(c) The Author(s) 2016. This article is published with open access at Springerlink.com

\begin{abstract}
Remote ischaemic conditioning (rIC) has demonstrated its effectiveness as a powerful cardioprotective tool in number of preclinical and limited clinical settings. More recently, ischaemic postconditioning given after an ischaemic event such as a myocardial infarction (MI) has shown not only to reduce infarct size but also to have beneficial effects on acute remodelling post-MI and to reduce the burden of heart failure and other detrimental outcomes. Building on this platform, repeated $\mathrm{rIC}$ over a number of days has the potential to augment the protective process even further. This review considers the current evidence base from which the concept of rIC in the setting of post-MI remodelling has grown. It also discusses the ongoing and planned clinical trials which are attempting to elucidate whether the protection imparted by rIC in the preclinical setting can be translated to the clinic and become a realistic weapon in the clinician's armoury to tackle acute remodelling and heart failure post-MI.
\end{abstract}

Keywords Cardioprotection - Heart failure .

Remodelling - Myocardial infarction - Remote ischaemic conditioning

\section{Introduction}

Remote ischaemic conditioning (rIC) is a non-invasive therapeutic technique whereby intermittent interruption of blood to an organ or muscle confers protection against

A. P. Vanezis

andrew.vanezis@nhs.net

1 Department of Cardiovascular Sciences, Glenfield General Hospital, University of Leicester, Leicester LE3 9QP, UK ischaemia/reperfusion (I/R) injury to a distant organ. RIC can be implemented prior to an expected ischaemic insult (preconditioning), during the evolution of an ischaemic insult (per-conditioning) or soon after the completion of an ischaemic insult (postconditioning). For the purposes of this review, the term rIC will encompass all of these techniques.

The technique evolved from the phenomenon of local ischaemic conditioning of the heart and has been successfully used to reduce myocardial damage and improve cardiovascular outcomes in the context of primary percutaneous intervention (PPCI) for acute myocardial infarction (MI) [1, 2], elective coronary angioplasty [3-5], coronary artery bypass surgery [6], valve surgery [7] and paediatric cardiac surgery [8]. Beyond the well-established acute protective phase, early preclinical studies have hinted at an additional role for rIC, predominantly in positively influencing post-MI ventricular remodelling. In addition to directly affecting final infarct size, rIC may act to increase recruitment of stunned myocardium as well as modulating remodelling processes such as cell death with an increased emphasis on autophagy, cardiomyocyte hypertrophy, extracellular matrix (ECM) changes and the influx of proinflammatory cells to the damaged myocardium. This potential new role for rIC may have a profound effect in reducing the incidence and impact of post-MI heart failure.

\section{Remodelling following myocardial infarction}

Heart failure is a major cause of long-term mortality and morbidity after MI. Analysis of registries and of large clinical trials across the western world, conducted in the era of acute revascularisation, has reported incidence rates of post-MI heart failure ranging from 10 to $50 \%$, depending on a number of factors including the degree and 
location of infarcted myocardium, how MI and heart failure were defined, whether there was pre-existing heart failure, the treatment modalities used and the characteristics of the populations analysed [9]. A retrospective analysis of Framingham Heart Study participants demonstrated an increase in the incidence of post-MI heart failure from the 1970 s to the 1990 s, closely linked to a decrease in mortality in acute MI, likely due to advances in myocardial salvage over this time period [10].

The development of chronic heart failure following MI most commonly results from adverse remodelling of the left ventricle, a process of structural reorganisation which occurs within the first few weeks to months after the acute event. Such remodelling is directly related to the extent of myocardial damage (due to initial necrosis and secondary apoptosis) and is most likely to occur following transmural infarction, as well as being heavily influenced by concomitant microvascular obstruction and lethal reperfusion injury in the era of acute revascularisation $[11,12]$. The process of remodelling is triggered by the initial ischaemia/reperfusion insult which sets into motion a number of events. In the initial stages, the changes in the left ventricle are predominantly due to the effects of infarct expansion causing cardiomyocyte necrosis and apoptosis which ultimately leads to myocardial wall dilatation via a number of mechanisms including changes in excitation-contraction coupling and an increased expression of foetal genes leading to an alteration in proteins produced. In the later stages, remodelling is largely fuelled by hypertrophy of surviving cardiomyocytes in response to pressure and volume changes and neurohumoral signalling, reorganisation of the ECM with deposition of scar tissue and an inflammatory-driven process whereby substantial ECM turnover in border areas leads to cell slippage and further dilatation. From a whole-organ perspective, these changes impact on cardiac dimensions and function. These initial changes act to maintain an adequate cardiac output in the face of a loss of functioning myocardium; however, over time remodelling becomes maladaptive. Indeed the extent and the nature of remodelling (both compensatory and subsequently maladaptive), and its progression is a powerful predictor for both heart failure and death following MI, as well as having prognostic implications for further MI, stroke and cardiac arrest $[13,14]$. Preventing or modifying some or all of the drivers for remodelling may go some way to reducing major adverse cardiovascular events in this setting.

\section{Local ischaemic conditioning}

In 1986, Murry et al. [15] first described an endogenous cardioprotective mechanism in a canine model of MI termed ischaemic preconditioning (IPC), whereby intermittent, non-lethal occlusion and reperfusion of the left anterior descending artery (LAD) immediately prior to a period of sustained occlusion significantly reduced the final infarct size. The first in vivo study in humans assessing the effect of preconditioning was performed by Deutsch et al. [16]. In a small group of patients undergoing elective PCI for an obstructed (LAD), they showed a reduction in electrographic, metabolic and clinical markers of ischaemia during the second cycle of balloon inflation compared to the first. Yellon et al. [17] later utilised IPC prior to coronary artery bypass grafting surgery (CABG), demonstrating preserved levels of myocardial adenosine triphosphate during cardiopulmonary bypass. Over the intervening years, evolution of this technique has seen it applied to situations of unpredictable cardiac ischaemia (as opposed to anticipated ischaemia from elective surgery). Zhao et al. [18] in 2003 introduced the concept of ischaemic postconditioning (IPostC) whereby the conditioning stimulus is applied immediately or soon after the index ischaemic event by intermittent inflations and deflations of the intracoronary balloon to stagger reperfusion. Using a canine model, they demonstrated the effectiveness of IPostC in the context of acute MI with comparable levels in infract size reduction and levels of tissue oedema as well as a variety of markers of cardiac damage when compared to IPC. The possible clinical applicability of IPostC in the setting of acute coronary events was quickly realised. By staggering reperfusion during $\mathrm{PCI}$ by repetitively inflating and deflating the angioplasty balloon in the culprit vessel for short periods of time, Laskey et al. [19] showed a reduction in final electrocardiographic ST-segment elevation size and an increase in distal myocardial perfusion. Staat et al. [20], using a similar technique at the time of PCI, showed a significant reduction in creatine kinase release and an increase in myocardial reperfusion in the conditioned group.

\section{Windows of protection and delayed conditioning}

Two distinct phases of cardioprotection resulting from ischaemic preconditioning have been shown to exist and are commonly termed 'windows of protection' [21]. The first window begins immediately following the conditioning stimulus and lasts up to $4 \mathrm{~h}$. Protection within this time period is mainly induced through posttranslational modification of proteins. The second or delayed window of protection occurs 12-72 $\mathrm{h}$ after the conditioning event and confers protection mainly through gene transcriptional changes [22-24].

In the context of protection against the long-term effects of $\mathrm{I} / \mathrm{R}$ and subsequent remodelling, the timing of the conditioning stimulus is paramount. Early studies suggested that to impart meaningful protection, conditioning must be 
implemented before, during or immediately after the clinical event as reperfusion injury is thought to occur within the first $15 \mathrm{~min}$ after the event. Dispelling this belief somewhat, Roubille et al. [25] described the damage associated with reperfusion as a 'wave front' and showed that $\mathrm{rIC}$ after $\mathrm{I} / \mathrm{R}$ can be effective up to $30 \mathrm{~min}$ post-MI. Basalay et al. [26] also found a similar but more modest phenomenon in a rat model of I/R where rIC was effective in reducing injury when started up to $10 \mathrm{~min}$ into reperfusion time. The ability to impart protection, even after a significant time after the acute event, may prove clinically useful in the context of protection against adverse remodelling in post-MI in patients presenting late to hospital, as the remodelling process continues to evolve for several days after the initial insult.

\section{Proposed mechanisms of remote ischaemic conditioning}

RIC took the concept of IPC a step further, allowing the conditioning stimulus to be applied away from the heart in a distant tissue bed. Przyklenk et al. [27] were the first to demonstrate rIC in an animal model of ischaemia/reperfusion. By preconditioning the left circumflex coronary (LCx) artery in dogs, they were able to protect the remote myocardium supplied by the LAD following transient ligation to induce MI and reperfusion. Kerendi et al. [28] later demonstrated the cardioprotective effects of rIC in the post-MI setting. After $30 \mathrm{~min}$ of coronary artery occlusion in rat hearts, they remotely conditioned the kidneys, then reperfused the heart and showed a $50 \%$ decrease in infarct size compared to the control.

In humans, the most practical application of rIC is by sequentially inflating a blood pressure cuff on the arm or leg, commonly using 3-4 cycles of inflation and deflation. This non-invasive technique affords protection not only to the heart but also to a number of other organs, most notably the brain and kidneys (for review, see Ref. [29]). Although the exact mechanisms of signal transduction from the tissue/organ undergoing rIC to the target organ have yet to be elucidated, various authors have highlighted the importance of humoral and neural signalling pathways as well as modulation of the systemic inflammatory response, perhaps working in an interdependent manner [30, 31].

The humoral signalling theory postulates that bloodborne factors are released locally by the tissue undergoing rIC and are then relayed in the blood to the target organ, where they bind to G-protein-coupled receptors triggering a number of intracellular signalling pathways. A number of research groups have illustrated the importance of humoral signalling by isolating naïve animal hearts and treating them with superfusate from rIC-treated animals or human donors and demonstrating cardioprotection [32, 33]. We have shown this in our laboratory using isolated adult rat cardiomyocytes [34]. Over the years, numerous humoral factors have been implicated including adenosine, bradykinin, nitrate/nitrites, opioid peptides, prostaglandins, natriuretic peptides, endocannabinoids, angiotensin I and calcitonin gene-related peptide. It is currently believed that the signalling factor(s) is between 3.5 and $15 \mathrm{kDa}$ in size and is hydrophobic $[35,36]$. More recent candidates for the responsible humoral messenger include stromal cellderived factor-1 (SDF-1a) which recruits stem cells and is activated by hypoxia [37], circulating extracellular vesicles [38] and a panel of anti-inflammatory proteins including haptoglobin and transthyretin [39].

The first evidence for the involvement of neural signalling in rIC was given by Gho et al. [40]. By administering intravenous hexamethonium (a ganglion blocker), they abolished protection afforded by remote ischaemic preconditioning of anterior mesenteric artery or renal artery against sustained MI. Subsequent experiments by Ding et al. [41] showed that by directly severing the renal nerve, one could abolish the cardioprotective effect of renal ischaemia rIC in rabbits. Mastitskaya et al. [42] proposed that rIC involves transmission via vagal preganglionic neurones, whilst further studies have advocated C-fibres as the sensory neural mechanism responsible for rIC [43]. Indeed there is some suggestion that a combined humoral/ neural signalling relay exists where adenosine (or other candidate factors) acts via modulation of afferent neural pathway [44]. Jensen et al. [45] demonstrated that the dialysates from type 2 diabetic individuals with peripheral neuropathy did not afford protection against infarction in a rabbit model, whereas the dialysate from non-diabetics and diabetics without peripheral neuropathy did, implying a fundamental role for neuronal signalling in this process. Furthermore, Basalay et al. [26] suggested that rIC in the pre-, per- and immediate post-MI period is heavily dependent on sympathetic messaging, whereas delayed remote ischaemic postconditioning i.e. $>10$ min after the event, appears not to rely so heavily on this neural signalling. This suggests a greater level of importance for humoral signalling in late postconditioning as well as potentially for repeated rIC.

A final hypothesised mechanism of rIC signalling involves modulation of the inflammatory response, important in initiating and controlling wound healing. Cheung et al. [8] demonstrated that patients given a rIC stimulus prior to undergoing open-heart surgery had a reduced systemic inflammatory response and reduced levels of cardiac damage. Li et al. [46] also highlighted the importance of inflammation by demonstrating a blunted cardioprotective response in mice deficient in $\mathrm{NF \kappa B}$ (a transcription factor involved in most inflammatory 
processes) subjected to rIC. The importance of NFאB was underlined by Wei et al. [47] in a rat model of repeated rIC and MI where they demonstrated significantly reduction in phosphorylation of the NFkB subunit p65 and its inhibitory protein I $\kappa \mathrm{B} \alpha$. In addition, this study showed a reduction in the infiltration of macrophages and neutrophils into the infarcted tissue in the rIC groups as well as a reduction in monocyte chemotactic protein 1 (MCP-1) in the border zone of infarcted tissue. More recently, Cai et al. [48] have shown up-regulation of expression of interleukin-10 (a potent anti-inflammatory cytokine) in a mouse model of rIC which leads to a reduction in myocardial infarct size and improved cardiac contractility.

Although some mystery still exists as to the mechanisms of rIC signalling, once the signal reaches the intended organ, the downstream intracellular pathways of rIC are thought to share much in common with local ischaemic conditioning. A number of intracellular pathways have been implicated including the reperfusion injury signalling kinase (RISK) pathway, involving ERK 1/2, p38 MAPK, PI3K-AKT and GSK3 $\beta$, acting ultimately to prevent opening of the mitochondrial permeability transition pore (mPTP) at the time of reperfusion. Another important downstream pathway is the survivor activating factor enhancement (SAFE) pathway, involving activation of the JAK-STAT3/5 axis, a protective transcription factor in the context of acute ischaemia (for a detailed review, see Ref. [49]). The first window of protection is thought to depend heavily on the RISK pathway, nitric oxide (NOS), PKC $\varepsilon$, $\mathrm{PKC} \gamma$ and reactive oxygen species. The second window of protection is more dependent on the SAFE pathway and inducible nitric oxide (iNOS) as well as retaining a significant overlap with some of the pathways implicated in the first window of protection [21, 50]. For a detailed discussion of our current understanding of the mechanisms of rIC, see the proceedings from the most recent Biennial Hatter Cardiovascular Institute Workshop [51].

\section{Remote ischaemic conditioning and acute myocardial infarction}

The simple and safe technique of inducing ischaemia by inflating a blood pressure cuff applied to the forearm to a level greater than the systolic blood pressure was first used in the setting of acute MI by Bøtker et al. [1] in the CONDI trial. In this landmark study $4 \times 5$-min cycles of blood pressure cuff inflation/deflation were applied to the forearm of a cohort of ST-segment elevation MI (STEMI) patients in the ambulance on-route to PPCI and showed that with large anterior MIs caused by total occlusion of the LAD, conditioned patients had a significantly better myocardial salvage index as assessed by gated single-photon emission
CT (SPECT) than the control group. A smaller study by Rentoukas et al. [2] was undertaken in STEMI patients where rIC was applied just after PCI using $4 \times 4$-min cycles of a forearm blood pressure cuff inflation/deflation in combination with morphine. There was a significant reduction in troponin $T$ levels in the conditioned group compared to the control group as well as ST-segment deviation resolution. More recent work by White and colleagues further demonstrated the benefits of rIC, implemented in this setting just prior to PPCI in the context of STEMI. They showed a reduction in myocardial oedema and infarct size as measured by cardiac magnetic resonance imaging (cMRI) as well as reduced levels of troponins in the conditioned group [52]. The excitement generated by these trials must be tempered by the difficulty in interpreting individual studies with small sample sizes and significant population heterogeneity which often assesses non-clinical outcome measures. Reassuringly, a recent comprehensive systematic review and meta-analysis of the available trial data by Le Page et al. [53] showed significant reductions in the hard end points of MACCE and allcause mortality in conditioned groups compared to controls in this setting.

\section{Remote ischaemic conditioning and remodelling postmyocardial infarction}

Thibault et al. first hinted at the prospect that the effects of local IPostC after an MI may have a positive influence on myocardial contractility [54]. They demonstrated a $7 \%$ greater left ventricular ejection fraction (LVEF) after 1 year compared with the control group $(p=0.04)$ [55]. Similarly, Munk et al. [54] in a sub-study of the CONDI trial showed that in MI patients with an area at risk (AAR) of over $35 \%$, those who received rIC immediately prior to PPCI had significant improvement in LVEF after 30 days compared to the control group (51 \pm 11 vs. $46 \pm 9 \%$, $p=0.03$ ). Furthermore, Hoole et al. [5], as well as demonstrating reduced levels of Troponin $T$ in patients undergoing elective PCI who received rIC compared to control, showed that at 6 months, the major adverse cardiac and cerebral event rate (MACCE) was lower in the rIC group ( 4 vs. 13 events, $p=0.018$ ). More recent data published by the CONDI investigators underlined some of the long-term benefits of rIC [56]. They followed 256 patients who had suffered a STEMI to a median of 3.8 years, split equally between those who had received rIC at the time of PPCI and those who had received PPCI only. MACCE occurred in $13.5 \%$ of the intervention group compared to $25.6 \%$ of the control group (HR 0.49, CI $0.27-0.89, p=0.018$ ). However, due to the small sample size, no solid inferences could be made about a 
number of secondary outcome measures, including the development of chronic heart failure.

In all these studies, one-off rIC at or around the time of MI has pointed towards the potential for this technique to reduce the incidence chronic heart failure. However, the degree to which the difference in LVEF and other markers of heart failure is due to remodelling, as opposed to attenuation of infarct size around the time of the acute event, is difficult to ascertain. Animal studies by Reddington's group have hinted that the progression to heart failure can be strongly attenuated, in a 'dose-dependent manner', by serial bouts of rIC soon after an ischaemic event. In a rat model of acute MI, Wei et al. [47] demonstrated the greatest improvement in LV chamber size, LV function and haemodynamic changes post-MI in the group that received repeated remote conditioning every day for 28 days compared to a control group and two groups receiving one-off applications of rIC either before or during ischaemia. The benefit appears to be in addition to the initial improvement seen due to reduction in infarct size and points towards novel mechanism of cardioprotection acting directly on remodelling. The study highlighted a variety of ways in which repeated rIC may work in this context including a reduction in oxidative stress, attenuation of the expression of genes associated with fibrosis and hypertrophy, and blunting of the inflammatory response with reduced levels of neutrophil and macrophage infiltration in the myocardium and reduced cytokine signalling. Previously, the same group had demonstrated that repetitive rIC significantly altered the behaviour of neutrophils after MI with reduced levels of adhesion at days 1 and 10 as well as a reduction in phagocytosis at day 10, apoptosis at days 1 and 10 and an overall change in the prolife of cytokine release [57]. More recent work from this group has suggested the existence of separate and very distinct mechanisms by which 'one-off' traditional rIC and repeated rIC infer protection. Whilst traditional rIC acts through the pathways described previously, repeated rIC was shown in this study to increased production of the autophagosome proteins LC3-II, cathepsin-L and Atg5 [58]. Yamaguchi et al. reinforced the power of repeated rIC post-MI and implicated exosomes as the mediators for signalling in rIC, possibly by their action of transferring anti-fibrotic microRNAs such as miR29a as well as IGF-1, which is known to be protective in the context of remodelling [59]. In addition, work by our laboratory showed that superfusate taken from ischaemic-conditioned Langendorff perfused rat hearts as well as serum taken from human volunteers immediately after undergoing rIC stimulation both independently inhibited endothelin-1-induced hypertrophy in a cellular model of hypertrophy alluding to a humoral mechanism of action [60].

\section{Future perspectives}

Multiple studies are underway to assess the impact of oneoff rIC protocols at the time of MI on various heart failurerelated outcome. Following on from the first CONDI study [56], CONDI-2 (Effect of RIC on Clinical Outcomes in STEMI Patients Undergoing PPCI) is well underway. This study aims to recruit 2300 participants over a 36-months period from a number of sites across Europe (http://www. clinicaltrials.gov/ct2/show/NCT01857414) with the primary outcome of assessing cardiovascular mortality and hospitalisation for heart failure at 1 year. Completion of the study is expected in late 2016. Running in collaboration with the CONDI-2 trial is the ERIC-PPCI (Effect of Remote Ischaemic Conditioning on clinical outcomes in ST-segment elevation myocardial infarction patients undergoing Primary Percutaneous Coronary Intervention) trial. This trial has recently started recruitment and aims to recruit 2000 participants in total across multiple sites to assess whether rIC at the time of PPCI for STEMI can reduce the combined primary outcome of cardiac death and hospitalisation for heart failure at 12 months (https://clin icaltrials.gov/ct2/show/NCT02342522).

DANAMI-3 (DANish Study of Optimal Acute Treatment of Patients with ST-elevation Myocardial Infarction) aims to assess the effect of local ischaemic conditioning on heart failure rates up to 3 years following PPCI for STEMI (http://clinicaltrials.gov/show/NCT01435408). The study has completed recruitment of over 2000 participants, and preliminary results pertaining to acute outcomes have previously been presented [61]. RECOND (Reduction in Infarct Size by Remote Per-postconditioning in Patients With ST-elevation Myocardial Infarction), a Swedish-led study, aims to recruit 120 participants and apply remote per-conditioning during PPCI for STEMI. One of the aims of the study is to compare cMRI-assessed remodelling parameters after 180 days between the conditioned and sham groups (https://clinicaltrials.gov/ct2/show/ NCT02021760). Finally, the RIC-STEMI trial (Remote Ischaemic Conditioning in ST-elevation Myocardial Infarction as Adjuvant to Primary Angioplasty) is a Portuguese-led study aiming to recruit 492 participants. Similarly, this study will recruit from patients suffering STEMI and undergoing PPCI with a 1:1 randomisation to rIC approximately $10 \mathrm{~min}$ prior to first angiographic balloon inflation or sham conditioning. Rather than cMRI-based outcomes, the primary endpoint in this study will be death or hospitalisation from heart failure at a minimum of 1 year (https://clinicaltrials.gov/ct2/show/NCT02313961).

Two phase II trials are underway with the hypothesis that chronic, repeated rIC use in the post-STEMI period can positively influence cardiac remodelling and reduce 
the incidence of and progression to heart failure: DREAM (Daily REmote Conditioning in Acute Myocardial Infarction) (http://clinicaltrials.gov/show/NCT01664611) and CRIC (Chronic Remote Ischaemic Conditioning to Modify Post-MI Remodelling) (http://clinicaltrials.gov/ show/NCT01817114). The DREAM study is a UK-based, multi-centre randomised control trial recruiting individuals who have suffered a STEMI and have had successful PPCI. Inclusion criteria includes post-STEMI LVEF $<45 \%$ on transthoracic echocardiography with no prior history of MI. The study aims to recruit 72 patients and is powered to detect a $5 \%$ increase in LVEF above natural recovery. Primary outcome data are obtained from baseline and 4-month cMRI to assess LVEF, left ventricular end diastolic volume and systolic volume, infarct size and oedema. An important facet of this trial is the intention to try and elucidate further our understanding of how much rIC in this context acts independently on remodelling when influences on the initial infarct size and MVO attenuation are reduced. This is done by beginning rIC 3 days after the acute event to avoid influencing the size of the infarct. RIC will continue for 4 weeks, performed daily by the participant. The study will randomise participants 50:50 in the intervention or the control group. The intervention group will receive a device that inflates to $200 \mathrm{mmHg}$ in $4 \times 5$-min cycles of inflation and deflation. The control group will receive identical-looking devices that cycle as the intervention group but only inflate to a maximum of $10 \mathrm{mmHg}$. As conditioning commences on day 3 post-MI, a greater focus is on the modulation of the remodelling process rather than the infarct sparing properties of rIC.

In a similar vein, the CRIC study is a multi-centre randomised controlled trial recruiting from a STEMI/PPCI population in Canada with a recruitment aim of 82. CRIC differs from DREAM in that the investigators will recruit left anterior descending (LAD) territory infarcts only and will exclude diabetic individuals. The reasons for focusing on non-diabetic patients who have suffered large anterior STEMIs in the CRIC study are based on prior work, suggesting that this group is most likely to respond to rIC and hence gains greater impact from the intervention [1, 62, 63]. Furthermore, rIC will start just prior to PPCI and continue for 4 weeks; therefore, rIC in this context will likely have an influence on infarct size and MVO as well as subsequent remodelling. Primary outcome will be obtained by comparing cMRI at baseline and 28 days, primarily to compare LVEDV. Both the DREAM and CRIC trials are nearing completion, and it is hoped that once these trials are completed we will be in a better position to assess the role of chronic rIC in remodelling and whether this technique merits investigation with larger phase III randomised control trials.

\section{Challenges of remote ischaemic conditioning}

The recent high-profile ERICCA trial, which showed no clinical outcome benefit at 1 year when using rIC compared to sham conditioning during elective on-pump CABG surgery, has tempered the enthusiasm in some quarters for $\mathrm{rIC}$ as a potential new cardioprotective therapy [64]. Pertaining to cardioprotection in the context of $\mathrm{MI}$ and remodelling, a number of key obstacles remain in effectively translating the protection afforded by rIC in animal and early clinical trials into larger clinical trials and ultimately into routine clinical practice.

One major challenge is that of timing of rIC. Patients having an MI presenting late to centres that can administer rIC may have completed their infarct and as such will derive minimal benefit from the procedure with regard to limiting I/R injury, although they may derive benefits from remodelling [65]. Similarly, patients presenting with small infarcts or those receiving PPCI or thrombolysis very early may derive little benefit from rIC as the scope for additional cardioprotection in this setting is limited [66, 67].

Another significant challenge is that of the large comorbidities and polypharmacy that is often encountered in the MI patient population. In particular type 2 diabetes, hyperlipidaemia, obesity and hypertension have all been shown to increase the threshold required for effective rIC [68]. Conversely, a number of the medications used in the context of MI or commonly taken by this group of patients already provide a significant degree of cardioprotection, namely ace inhibitors, statins, opioids, insulin and a number of oral hypoglycaemic agents including metformin [69]. There are also a few medication that can inhibit the effects of rIC including sulfonylureas [70]. These issues muddy the waters and make trial design and subsequent clinical translation challenging.

Finally, from a practical perspective, because rIC involves the application of a device on the arm that requires a number of inflation and deflation cycles, even with the use of an automated device, this can pose logistical problems in the ambulance or the catheter laboratory during PPCI where time is of the essence and gaining arterial and venous access with the cuff in situ may pose an issue. Furthermore, in scenarios, where rIC must be administered on a regular basis by the patient to target remodelling post-MI, the authors foresee significant concordance issues which may limit the therapy in this context. The use of automated rIC devices that can be interrogated may go some way to overcomeing this issue.

\section{Conclusions}

RIC is only now beginning to reach its translational potential with regard to protection from ischaemic/reperfusion injury. Long-term outcome data for one-off rIC at 
the time of MI are awaited from the CONDI-2, ERICPPCI, DANAMI-3, RECOND and RIC-STEMI trials to supplement promising results from smaller preliminary studies. It is yet to be established whether early preclinical data suggesting a clinically useful role for chronic, repeated rIC use in the context of post-MI remodelling will be borne out in the trial data, but it is hoped that results from both the DREAM and CRIC trials will go some way to answering this question and potentially open the door for larger clinical trials to follow.

Acknowledgments APV would like to acknowledge the generous funding received by the NIHR Leicester Cardiovascular Biomedical Research Unit.

\section{Compliance with ethical standards}

Conflict of interests The authors declare that they have no competing interests. In addition, the authors have no affiliations or financial involvement with any organisation or entity with a financial interest in or financial conflict with the subject matter or materials discussed in the manuscript.

Open Access This article is distributed under the terms of the Creative Commons Attribution 4.0 International License (http://crea tivecommons.org/licenses/by/4.0/), which permits unrestricted use, distribution, and reproduction in any medium, provided you give appropriate credit to the original author(s) and the source, provide a link to the Creative Commons license, and indicate if changes were made.

\section{References}

1. Bøtker HE, Kharbanda R, Schmidt MR, Bøttcher M, Kaltoft AK, Terkelsen CJ, Munk K, Andersen NH, Hansen TM, Trautner S, Lassen JF, Christiansen EH, Krusell LR, Kristensen SD, Thuesen L, Nielsen SS, Rehling M, Sørensen HT, Redington AN, Nielsen TT (2010) Remote ischaemic conditioning before hospital admission, as a complement to angioplasty, and effect on myocardial salvage in patients with acute myocardial infarction: a randomised trial. Lancet 375:727-734. doi:10.1016/s0140-6736 (09)62001-8

2. Rentoukas I, Giannopoulos G, Kaoukis A, Kossyvakis C, Raisakis K, Driva M, Panagopoulou V, Tsarouchas K, Vavetsi S, Pyrgakis V, Deftereos S (2010) Cardioprotective role of remote ischemic periconditioning in primary percutaneous coronary intervention: enhancement by opioid action. J Am Coll Cardiol Interv 3:49-55. doi:10.1016/j.jcin.2009.10.015

3. Luo SJ, Zhou YJ, Shi DM, Ge HL, Wang JL, Liu RF (2013) Remote ischemic preconditioning reduces myocardial injury in patients undergoing coronary stent implantation. Can J Cardiol 29:1084-1089. doi:10.1016/j.cjca.2012.11.022

4. Ahmed RM, el Mohamed HA, Ashraf M, Maithili S, Nabil F, Rami R, Mohamed TI (2013) Effect of remote ischemic preconditioning on serum troponin $\mathrm{T}$ level following elective percutaneous coronary intervention. Catheter Cardiovasc Interv 82:18

5. Hoole SP, Heck PM, Sharples L, Khan SN, Duehmke R, Densem CG, Clarke SC, Shapiro LM, Schofield PM, O'Sullivan M, Dutka DP (2009) Cardiac remote ischemic preconditioning in coronary stenting (CRISP Stent) study: a prospective, randomized control trial. Circulation 119:820-827. doi:10.1161/circulationaha.108. 809723

6. Thielmann M (2013) Cardioprotective and prognostic effects of remote ischaemic preconditioning in patients undergoing coronary artery bypass surgery: a single-centre randomised, doubleblind, controlled trial. Lancet 382:597-604

7. Xie JJ, Liao XL, Chen WG, Huang DD, Chang FJ, Chen W, Luo ZL, Wang ZP, Ou JS (2012) Remote ischaemic preconditioning reduces myocardial injury in patients undergoing heart valve surgery: randomised controlled trial. Heart 98:384-388. doi:10. 1136/heartjnl-2011-300860

8. Cheung MMH, Kharbanda RK, Konstantinov IE, Shimizu M, Frndova H, Li J, Holtby HM, Cox PN, Smallhorn JF, Van Arsdell GS, Redington AN (2006) Randomized controlled trial of the effects of remote ischemic preconditioning on children undergoing cardiac surgery: first clinical application in humans. J Am Coll Cardiol 47:2277-2282. doi:10.1016/j.jacc.2006.01.066

9. Weir RA, McMurray JJ, Velazquez EJ (2006) Epidemiology of heart failure and left ventricular systolic dysfunction after acute myocardial infarction: prevalence, clinical characteristics, and prognostic importance. Am J Cardiol 97(10A):13F-25F. doi:10. 1016/j.amjcard.2006.03.005

10. Velagaleti RS, Pencina MJ, Murabito JM, Wang TJ, Parikh NI, D'Agostino RB, Levy D, Kannel WB, Vasan RS (2008) Longterm trends in the incidence of heart failure after myocardial infarction. Circulation 118:2057-2062. doi:10.1161/circulatio naha.108.784215

11. Ndrepepa G, Mehilli J, Kastrati A, Schömig A, Schwaiger M, Martinoff S (2007) Evolution of left ventricular ejection fraction and its relationship to infarct size after acute myocardial infarction. J Am Coll Cardiol 50:149-156. doi:10.1016/j.jacc.2007.03.034

12. Garcia-Dorado D, Ruiz-Meana M, Piper HM (2009) Lethal reperfusion injury in acute myocardial infarction: facts and unresolved issues. Cardiovasc Res 83(2):165-168. doi:10.1093/ cvr/cvp185

13. White $\mathrm{H}$, Norris R, Brown M, Brandt P, Whitlock R, Wild C (1987) Left ventricular end-systolic volume as the major determinant of survival after recovery from myocardial infarction. Circulation 76:44-51. doi:10.1161/01.cir.76.1.44

14. Verma A, Meris A, Skali H, Ghali JK, Arnold JMO, Bourgoun M, Velazquez EJ, McMurray JJV, Kober L, Pfeffer MA, Califf RM, Solomon SD (2008) Prognostic implications of left ventricular mass and geometry following myocardial infarction: the VALIANT (VALsartan In Acute myocardial iNfarcTion) Echocardiographic Study. J Am Coll Cardiol Imaging 1:582-591. doi:10. 1016/j.jcmg.2008.05.012

15. Murry CE, Reimer KA, Jennings RB (1986) Preconditioning with ischemia: a delay of lethal cell injury in ischemic myocardium. Circulation 74:1124-1136

16. Deutsch E, Berger M, Kussmaul WG, Hirshfeld JW, Herrmann HC, Laskey WK (1990) Adaptation to ischemia during percutaneous transluminal coronary angioplasty. Clinical, hemodynamic, and metabolic features. Circulation 82(6):2044-2051. doi:10.1161/ 01.cir.82.6.2044

17. Yellon DM, Alkhulaifi AM, Pugsley WB (1993) Preconditioning the human myocardium. Lancet 342:276-277

18. Zhao Z-Q, Faraz K, Michael EH, Joel SC, Wang N-P, Guyton RA, Vinten-Johansen J (2003) Inhibition of myocardial injury by ischemic postconditioning during reperfusion: comparison with ischemic preconditioning. Am J Physiol 54:H579

19. Laskey WK (2005) Brief repetitive balloon occlusions enhance reperfusion during percutaneous coronary intervention for acute myocardial infarction: a pilot study. Catheter Cardiovasc Interv 65:361-367. doi:10.1002/ccd.20397

20. Staat P, Ovize M, Bonnefoy E, André-Fouët X, Aupetit J-F, L'Huillier I, Cottin Y, Cung TT, Piot C, Rioufol G, Finet G 
(2005) Postconditioning the human heart. Circulation 112:2143-2148. doi:10.1161/circulationaha.105.558122

21. Hausenloy D, Yellon D (2010) The second window of preconditioning (SWOP) where are we now? Cardiovasc Drugs Ther 24:235-254. doi:10.1007/s10557-010-6237-9

22. Marber M, Latchman D, Walker J, Yellon D (1993) Cardiac stress protein elevation 24 hours after brief ischemia or heat stress is associated with resistance to myocardial infarction. Circulation 88:1264-1272. doi:10.1161/01.cir.88.3.1264

23. Kuzuya T, Hoshida S, Yamashita N, Fuji H, Oe H, Hori M, Kamada T, Tada M (1993) Delayed effects of sublethal ischemia on the acquisition of tolerance to ischemia. Circ Res 72:1293-1299. doi:10.1161/01.res.72.6.1293

24. Ren C, Yan Z, Wei D, Gao X, Chen X, Zhao H (2009) Limb remote ischemic postconditioning protects against focal ischemia in rats. Brain Res 1288:88-94. doi:10.1016/j.brainres.2009.07. 029

25. Roubille F, Covinhes A, Nargeot J, Piot C, Franck-Miclo A, Redt-Clouet C, Lafont C, Combes S, Cransac F, SportouchDukhan C, Vincent A, Barrère-Lemaire S, Fontanaud P (2011) Delayed postconditioning in the mouse heart in vivo. Circulation 124:1330

26. Basalay M, Barsukevich V, Mastitskaya S, Mrochek A, Pernow J, Sjöquist P-O, Ackland GL, Gourine AV, Gourine A (2012) Remote ischaemic pre- and delayed postconditioning-similar degree of cardioprotection but distinct mechanisms. Exp Physiol 97:908-917. doi:10.1113/expphysiol.2012.064923

27. Przyklenk K, Bauer B, Ovize M, Kloner RA, Whittaker P (1993) Regional ischemic 'preconditioning' protects remote virgin myocardium from subsequent sustained coronary occlusion. Circulation (New York, NY) 87:893

28. Kerendi F, Kin H, Halkos ME, Jiang R, Zatta AJ, Zhao ZQ, Guyton RA, Vinten-Johansen J (2005) Remote postconditioning. Basic Res Cardiol 100:404-412. doi:10.1007/s00395-005-0539-2

29. Candilio L, Malik A, Hausenloy DJ (2013) Protection of organs other than the heart by remote ischemic conditioning. J Cardiovasc Med 14:193-205

30. Lim S, Yellon D, Hausenloy D (2010) The neural and humoral pathways in remote limb ischemic preconditioning. Basic Res Cardiol 105:651-655. doi:10.1007/s00395-010-0099-y

31. Hausenloy DJ, Yellon DM (2008) Remote ischaemic preconditioning: underlying mechanisms and clinical application. Cardiovasc Res 79:377-386. doi:10.1093/cvr/cvn114

32. Dickson EW, Lorbar M, Porcaro WA, Fenton RA, Reinhardt CP, Gysembergh A, Przyklenk K (1999) Rabbit heart can be "preconditioned" via transfer of coronary effluent. AJP-Heart 277:H2451-H2457

33. Breivik L, Helgeland E, Aarnes EK, Mrdalj J, Jonassen AK (2011) Remote postconditioning by humoral factors in effluent from ischemic preconditioned rat hearts is mediated via PI3K/ Akt-dependent cell-survival signaling at reperfusion. Basic Res Cardiol 106:135-145

34. Turrell HE, Thaitirarot C, Crumbie H, Rodrigo G (2014) Remote ischemic preconditioning of cardiomyocytes inhibits the mitochondrial permeability transition pore independently of reduced calcium-loading or sarcKATP channel activation. Physiol Rep. doi:10.14814/phy2.12231

35. Serejo FC, Rodrigues LFJ, da Silva Tavares KC, de Carvalho ACC, Nascimento JHM (2007) Cardioprotective properties of humoral factors released from rat hearts subject to ischemic preconditioning. J Cardiovasc Pharmacol 49:214-220

36. Shimizu M, Tropak M, Diaz R, Suto F, Surendra H, Kuzmin E, Li J, Gross G, Wilson G, Callahan J, Redington A (2009) Transient limb ischaemia remotely preconditions through a humoral mechanism acting directly on the myocardium: evidence suggesting cross-species protection. Clin Sci (Lond) 117:191-200
37. Davidson S, Selvaraj P, He D, Boi-Doku C, Yellon R, Vicencio J, Yellon D (2013) Remote ischaemic preconditioning involves signalling through the SDF-1 $\alpha /$ CXCR4 signalling axis. Basic Res Cardiol 108:1-10. doi:10.1007/s00395-013-0377-6

38. Giricz Z, Varga ZV, Baranyai T, Sipos P, Paloczi K, Kittel A, Buzas EI, Ferdinandy P (2014) Cardioprotection by remote ischemic preconditioning of the rat heart is mediated by extracellular vesicles. J Mol Cell Cardiol 68:75-78. doi:10.1016/j. yjmcc.2014.01.004

39. Hibert P, Prunier-Mirebeau D, Beseme O, Chwastyniak M, Tamareille S, Pinet F, Prunier F (2014) Modifications in rat plasma proteome after remote ischemic preconditioning (RIPC) stimulus: identification by a SELDI-TOF-MS approach. PLoS ONE 9:13

40. Gho BCG, Schoemaker RG, van den Doel MA, Duncker DJ, Verdouw PD (1996) Myocardial protection by brief ischemia in noncardiac tissue. Circulation 94:2193-2200. doi:10.1161/01.cir. 94.9.2193

41. Ding Y, Zhang M, He R (2001) Role of renal nerve in cardioprotection provided by renal ischemic preconditioning in anesthetized rabbits. Sheng Li Xue Bao 53:7-12

42. Mastitskaya S, Marina N, Gourine A, Gilbey MP, Spyer KM, Teschemacher AG, Kasparov S, Trapp S, Ackland GL, Gourine AV (2012) Cardioprotection evoked by remote ischaemic preconditioning is critically dependent on the activity of vagal preganglionic neurones. Cardiovasc Res 95:487-494

43. Brzozowski T, Konturek PC, Konturek SJ, Pajdo R, Kwiecien S, Pawlik M, Drozdowicz D, Sliwowski Z, Pawlik WW (2004) Ischemic preconditioning of remote organs attenuates gastric ischemia-reperfusion injury through involvement of prostaglandins and sensory nerves. Eur J Pharmacol 499:201-213. doi:10.1016/j.ejphar.2004.07.072

44. Liem DA, Verdouw PD, Ploeg H, Kazim S, Duncker DJ (2002) Sites of action of adenosine in interorgan preconditioning of the heart. Am J Physiol Heart Circ Physiol 283:H29-H37

45. Jensen R, Støttrup N, Kristiansen S, Bøtker H (2012) Release of a humoral circulating cardioprotective factor by remote ischemic preconditioning is dependent on preserved neural pathways in diabetic patients. Basic Res Cardiol 107(5):1-9. doi:10.1007/ s00395-012-0285-1

46. Li G, Labruto F, Sirsjö A, Chen F, Vaage J, Valen G (2004) Myocardial protection by remote preconditioning: the role of nuclear factor kappa-B p105 and inducible nitric oxide synthase. Eur J Cardiothorac Surg 26:968-973. doi:10.1016/j.ejcts.2004.06. 015

47. Wei M, Redington AN, Liu M, Tao J, Xin P, Zhu W, Li J, Li J, Li Y, Li S (2011) Repeated remote ischemic postconditioning protects against adverse left ventricular remodeling and improves survival in a rat model of myocardial infarction. Circ Res 108:1220-1225. doi:10.1161/circresaha.110.236190

48. Cai ZP, Parajuli N, Zheng X, Becker L (2012) Remote ischemic preconditioning confers late protection against myocardial ischemia-reperfusion injury in mice by upregulating interleukin10. Basic Res Cardiol 107:012-0277

49. Sandrine L (2009) Activation of the protective Survivor Activating Factor Enhancement (SAFE) pathway against reperfusion injury: does it go beyond the RISK pathway? J Mol Cell Cardiol 47:32-40. doi:10.1016/j.yjmcc.2009.03.019

50. Imagawa J, Yellon DM, Baxter GF (1999) Pharmacological evidence that inducible nitric oxide synthase is a mediator of delayed preconditioning. Br J Pharmacol 126(3):701-708. doi:10. 1038/sj.bjp.0702368

51. Pickard JM, Botker HE, Crimi G, Davidson B, Davidson SM, Dutka D, Ferdinandy P, Ganske R, Garcia-Dorado D, Giricz Z, Gourine AV, Heusch G, Kharbanda R, Kleinbongard P, MacAllister R, McIntyre C, Meybohm P, Prunier F, Redington A, 
Robertson NJ, Suleiman MS, Vanezis A, Walsh S, Yellon DM, Hausenloy DJ (2015) Remote ischemic conditioning: from experimental observation to clinical application: report from the 8th Biennial Hatter Cardiovascular Institute Workshop. Basic Res Cardiol 110(1):453. doi:10.1007/s00395-014-0453-6

52. White SK, Frohlich GM, Sado DM, Maestrini V, Fontana M, Treibel TA, Tehrani S, Flett AS, Meier P, Ariti C, Davies JR, Moon JC, Yellon DM, Hausenloy DJ (2015) Remote ischemic conditioning reduces myocardial infarct size and edema in patients with ST-segment elevation myocardial infarction. JACC Cardiovasc Interv 8(1 Pt B):178-188. doi:10.1016/j.jcin.2014.05. 015

53. Le Page S, Bejan-Angoulvant T, Angoulvant D, Prunier F (2015) Remote ischemic conditioning and cardioprotection: a systematic review and meta-analysis of randomized clinical trials. Basic Res Cardiol 110(2):11. doi:10.1007/s00395-015-0467-8

54. Munk K, Andersen NH, Schmidt MR, Nielsen SS, Terkelsen CJ, Sloth E, Bøtker HE, Nielsen TT, Poulsen SH (2010) Remote ischemic conditioning in patients with myocardial infarction treated with primary angioplasty/clinical perspective. Circ Cardiovasc Imaging 3:656-662. doi:10.1161/circimaging.110. 957340

55. Thibault H, Rossi R, Macia JC, Bonnefoy E, André-Fouët X, Bontemps L, Angoulvant D, Sportouch C, Raczka F, Kirkorian G, Cung TT, Piot C, Finet G, Itti R, Derumeaux G, Ovize M, Aupetit J-F, Staat P, Rioufol G (2008) Long-term benefit of postconditioning. Circulation 117:1037

56. Sloth AD, Schmidt MR, Munk K, Kharbanda RK, Redington AN, Schmidt M, Pedersen L, Sørensen HT, Bøtker HE, Investigators C (2013) Improved long-term clinical outcomes in patients with ST-elevation myocardial infarction undergoing remote ischaemic conditioning as an adjunct to primary percutaneous coronary intervention. Eur Heart J. doi:10.1093/eurheartj/eht369

57. Shimizu M, Saxena P, Konstantinov IE, Cherepanov V, Cheung MMH, Wearden P, Zhangdong H, Schmidt M, Downey GP, Redington AN (2010) Remote ischemic preconditioning decreases adhesion and selectively modifies functional responses of human neutrophils. J Surg Res 158:155-161. doi:10.1016/j.jss. 2008.08.010

58. Rohailla S, Clarizia N, Sourour M, Sourour W, Gelber N, Wei C, Li J, Redington AN (2014) Acute, delayed and chronic remote ischemic conditioning is associated with downregulation of mTOR and enhanced autophagy signaling. PLoS ONE 9(10):e111291. doi:10.1371/journal.pone.0111291

59. Yamaguchi T, Izumi Y, Nakamura Y, Yamazaki T, Shiota M, Sano S, Tanaka M, Osada-Oka M, Shimada K, Miura K, Yoshiyama M, Iwao H (2015) Repeated remote ischemic conditioning attenuates left ventricular remodeling via exosome-mediated intercellular communication on chronic heart failure after myocardial infarction. Int J Cardiol 178:239-246. doi:10.1016/j. ijcard.2014.10.144

60. Vanezis AP, Edroos SA, Samani NJ, Rodrigo GC (2012) The inhibitory effect of remote ischaemic conditioning on a cellular model of cardiac hypertrophy. Heart 98(Suppl 5):A4-A5. doi:10. 1136/heartjnl-2012-303148a.13

61. Høfsten DE, Kelbæk H, Helqvist S, Kløvgaard L, Holmvang L, Clemmensen P, Torp-Pedersen C, Tilsted H-H, Bøtker HE, Jensen LO, Køber L, Engstrøm T (2015) The third danish study of optimal acute treatment of patients with ST-segment elevation myocardial infarction: ischemic postconditioning or deferred stent implantation versus conventional primary angioplasty and complete revascularization versus treatment of culprit lesion only. Am Heart J 169(5):613-621. doi:10.1016/j.ahj.2015.02.004

62. Ishihara M, Inoue I, Kawagoe T, Shimatani Y, Kurisu S, Nishioka K, Kouno Y, Umemura T, Nakamura S, Sato H (2001) Diabetes mellitus prevents ischemic preconditioning in patients with a first acute anterior wall myocardial infarction. J Am Coll Cardiol 38:1007-1011

63. Miki T, Itoh T, Sunaga D, Miura T (2012) Effects of diabetes on myocardial infarct size and cardioprotection by preconditioning and postconditioning. Cardiovasc Diabetol 11:67

64. Hausenloy DJ, Candilio L, Evans R, Ariti C, Jenkins DP, Kolvekar S, Knight R, Kunst G, Laing C, Nicholas J, Pepper J, Robertson S, Xenou M, Clayton T, Yellon DM (2015) Remote ischemic preconditioning and outcomes of cardiac surgery. N Engl J Med 373(15):1408-1417. doi:10.1056/NEJMoa1413534

65. Schomig A, Mehilli J, Antoniucci D, Ndrepepa G, Markwardt C, Di Pede F, Nekolla SG, Schlotterbeck K, Schuhlen H, Pache J, Seyfarth M, Martinoff S, Benzer W, Schmitt C, Dirschinger J, Schwaiger M, Kastrati A (2005) Mechanical reperfusion in patients with acute myocardial infarction presenting more than 12 hours from symptom onset: a randomized controlled trial. JAMA 293(23):2865-2872. doi:10.1001/jama.293.23.2865

66. Miura T, Miki T (2008) Limitation of myocardial infarct size in the clinical setting: current status and challenges in translating animal experiments into clinical therapy. Basic Res Cardiol 103(6):501-513. doi:10.1007/s00395-008-0743-y

67. Roubille F, Mewton N, Elbaz M, Roth O, Prunier F, Cung TT, Piot C, Roncalli J, Rioufol G, Bonnefoy-Cudraz E, Wiedemann JY, Furber A, Jacquemin L, Willoteaux S, Abi-Khallil W, Sanchez I, Finet G, Sibellas F, Ranc S, Boussaha I, Croisille P, Ovize M (2014) No post-conditioning in the human heart with thrombolysis in myocardial infarction flow 2-3 on admission. Eur Heart J 35(25):1675-1682. doi:10.1093/eurheartj/ehu054

68. McCafferty K, Forbes S, Thiemermann C, Yaqoob MM (2014) The challenge of translating ischemic conditioning from animal models to humans: the role of comorbidities. Dis Models Mech 7(12):1321-1333. doi:10.1242/dmm.016741

69. Sivaraman V, Yellon DM (2014) Pharmacologic therapy that simulates conditioning for cardiac ischemic/reperfusion injury. J Cardiovasc Pharmacol Ther 19(1):83-96. doi:10.1177/ 1074248413499973

70. Cleveland JC Jr, Meldrum DR, Cain BS, Banerjee A, Harken AH (1997) Oral sulfonylurea hypoglycemic agents prevent ischemic preconditioning in human myocardium. Two paradoxes revisited. Circulation 96(1):29-32 